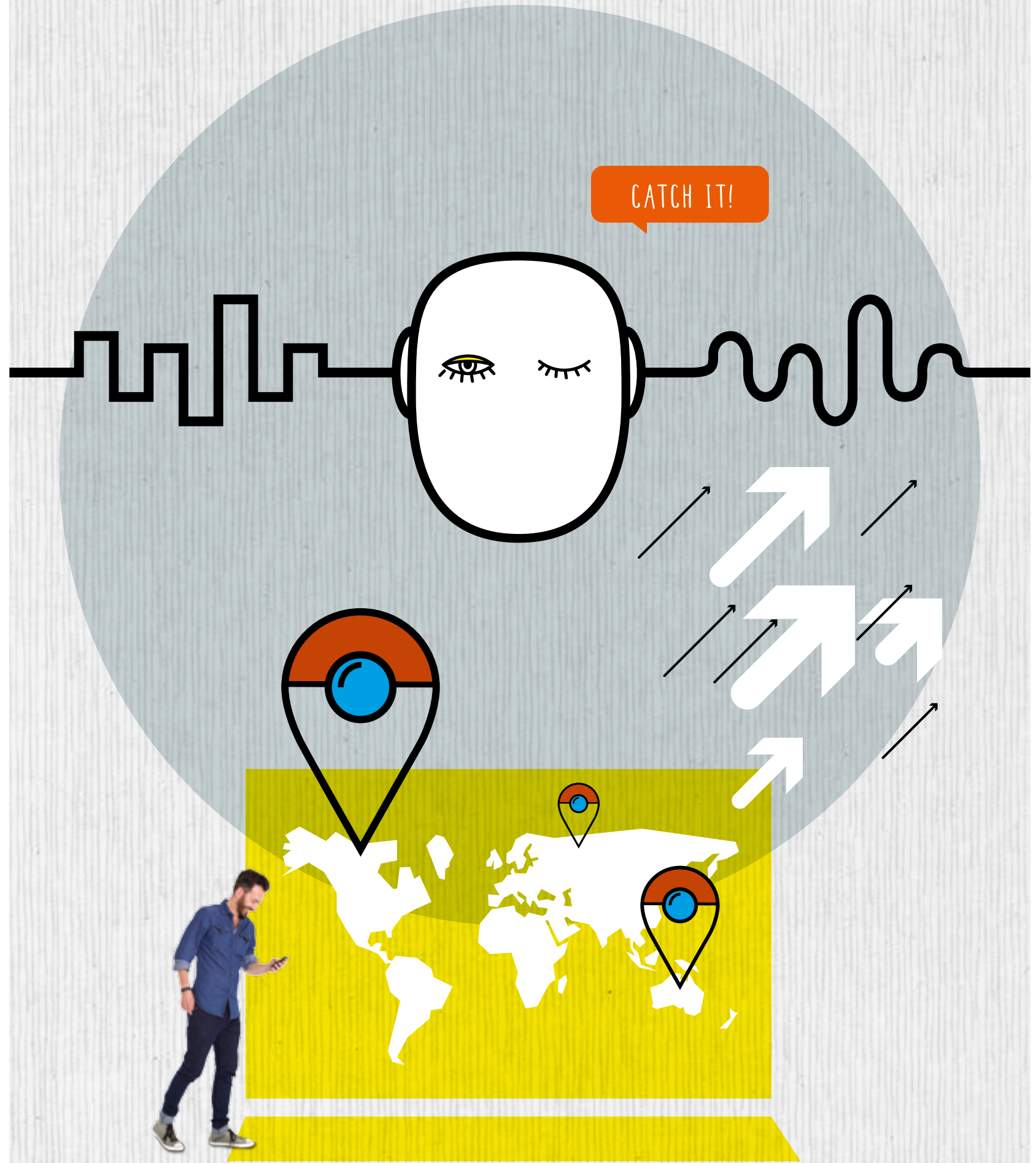




\title{
Business Model Innovation: How to Create Value in a Digital World
}

\author{
Christoph Zott and Raphael Amit
}

\author{
na \\ KEYWORDS \\ Activity System, Business Model Innovation, \\ Digital Innovation, Pokémon GO, \\ Value Creation \\ THE AUTHORS \\ Christoph Zott, \\ Professor of Entrepreneurship, \\ IESE Business School in Barcelona, \\ University of Navarra, Spain \\ CZott@iese.edu \\ Raphael Amit, \\ Robert B. Goergen Professor of \\ Entrepreneurial Management, Wharton School, \\ University of Pennsylvania Philadelphia, PA, USA \\ amit@wharton.upenn.edu
}

Digital innovation - one man's meat is another man's poison /// The digitalization of ever more aspects of consumers' lives gives rise to enormous opportunities for the creation of new wealth. New apps, new service, new platforms, new data and new devices have become a crowded playground for all kinds of companies that want to tap emerging chances. New companies have entered the scene, sometimes with remarkable success and breathtaking growth. Facebook, founded in 2004, was generating revenues of US\$19 billion by 2015 . Or take Airbnb - it was founded in 2008 and was soon nearing revenues of US\$1 billion, also in 2015. While new startups are in a gold-rush mood, many established companies find themselves with their backs to the wall. Traditional retailers, banks, travel agencies, print media and many more are experiencing hard times and fighting to survive. At first sight, entrenched and new players do not have much in common, but when one takes a closer look, it becomes clear that both types of companies face the same challenge: They need to develop new business models that work in the digital world and create value for connected customers.

New technologies - new value chain /// Digitalization came hand in hand with product innovation, from faster personal computers and better smartphones to wearable technology. Now we're moving towards smart-just-abouteverything. But all these new products, applications and services are changing our lives in radical ways. It is not only products or services that become obsolete but also organizational processes and systems because they simply no longer create enough value. To seamlessly account for the digitalization of the business and the customer side, new ideas are mandatory, and, increasingly, the whole business model is the new source of innovation. Business model inno- 
FIGURE 1:

\section{Elements of successful business model innovation}

New Buisness Model

Why?

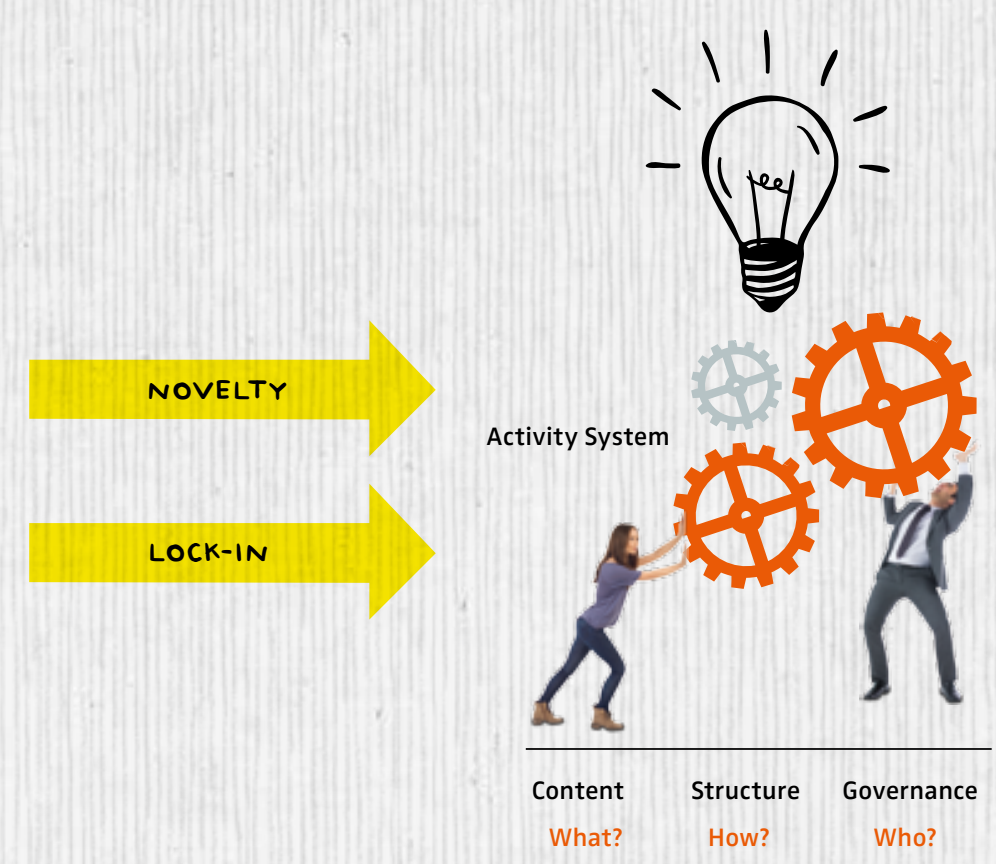

COMPLEMENTARITIES

EFFICIENCY

vation is a complete reconfiguration of how a company does business. Its design is one of the most fundamental strategic choices that entrepreneurs and managers can make because it defines how a company taps into the networks of companies and institutions and customers that surround it. It might bring together previously unconnected players; it may link current players in new ways. It can introduce completely new digitally supported activities and drop redundant ones. It stakes out friends and foes and helps companies make crucial decisions when it comes to anchoring their competitive advantage in a digital world. Innovating the business model can bring tremendous value to stakeholders. A smartly designed new business model can increase the total value created for all stakeholders, including customers, partners and suppliers.
Reinventing a company's entire activity system /// The business model can be described as a system of interconnected and interdependent activities that determines the way the company "does business" with its stakeholders. In other words, a business model is a bundle of specific activities - an activity system - conducted to satisfy the perceived needs of the market. It specifies which parties within or as business partners conduct which activities, and how these activities are linked to each other. The three design elements that characterize a company's activity system are content, structure and governance. Changing one or more of these elements means changing the whole model. If the new business model is "new to the world" and not just "new to the company" it represents a business model innovation (see Figure 1). 


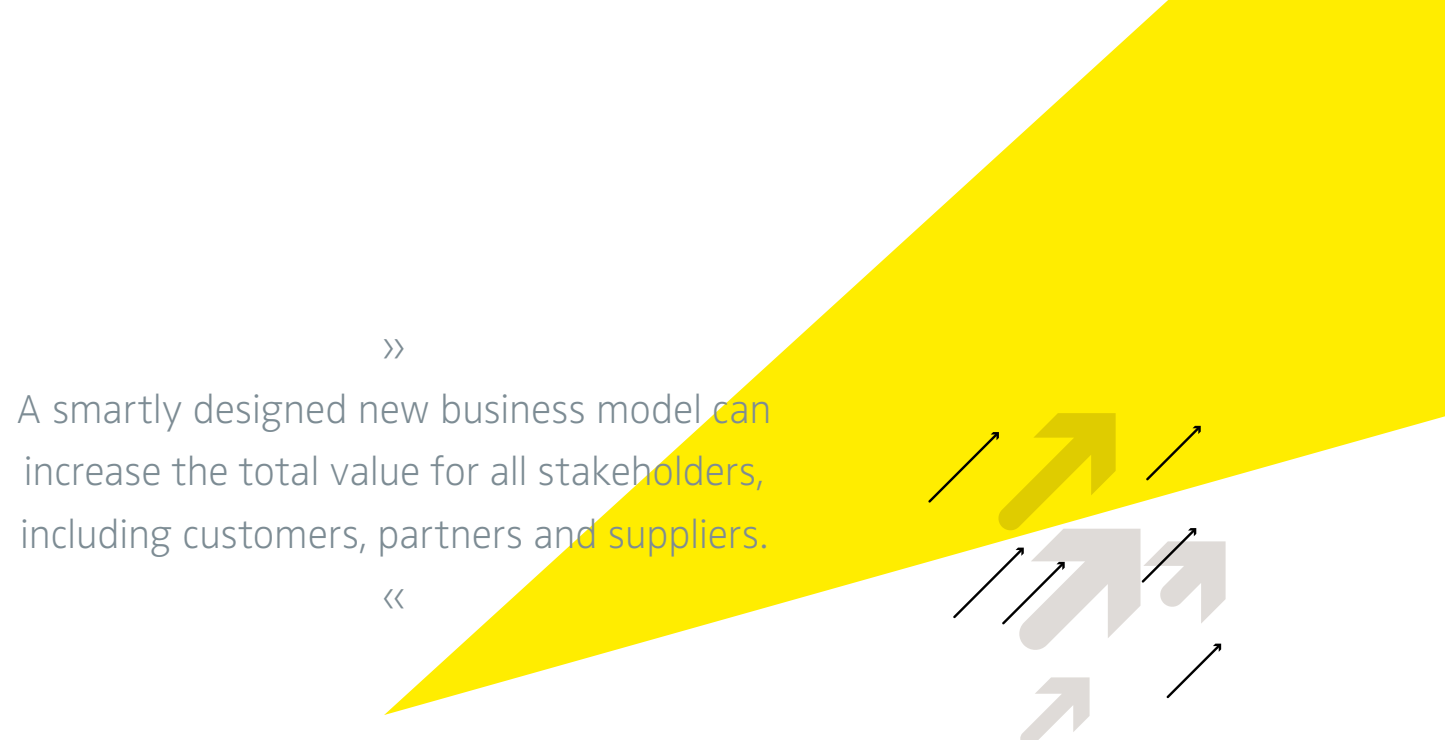

The content of an activity system refers to the selection of activities to be performed; you can also call it the WHAT of the activity system. For example, after a severe financial crisis in the early 1990s, IBM shifted its focus from being a supplier of hardware to becoming a service provider. Drawing on know-how built over decades, IBM launched a range of new activities in consulting, IT maintenance and other services. The transformation was substantial: By 2009, more than half of IBM's US\$96 billion in revenues came from these activities, which had barely existed 15 years earlier.

The structure of an activity system describes how the activities are linked and in what sequence; you can also call it the HOW of the activity system. The online travel agency Priceline.com, for instance, has established links with airline companies, credit card companies and Travelport's Worldspan central reservation system, among others. By introducing a reverse market in which customers post desired prices for the sellers to accept, Priceline developed a fundamentally novel exchange mechanism through which these parties interact and by which items such as airline tickets are sold. Priceline was granted a business method patent on its innovative activity system - a novel structure that continues to distinguish the company from other travel agencies.

The governance of an activity system refers to who performs the activities; you can also call it the WHO of the activity system. An example of an innovative governance structure is the recent formation of a consortium of magazine publishers, including Time, Hearst, Meredith and Condé Nast, to develop an online magazine newsstand using multiple digital formats. The resulting company Next Issue Media, is jointly owned by industry rivals and represents a response by competing publishers to declining print circulation and print advertising revenue and to the growth of digital media. Fighting for survival, the publishers are looking beyond their otherwise fierce competition to their common interests and are offering the app Texture, a new context for magazines in the digital era. Texture plans offer unlimited access to an expansive catalog of magazines - including back issues - for one low monthly price.

Value Drivers for Business Models /// But how does a company increase the odds of developing the right business model for its situation? In our earlier work, we identified four major interlinked value drivers of business models: novelty, lock-in, complementarities and efficiency.

Novelty captures the degree of business model innovation that is embodied by the activity system. Consider Airbnb's idea of sharing one's living space with paying guests and its sophisticated translation into a sharing platform. This business model was something really new. Or consider Nintendo's remarkable move with Pokémon GO (see Box).

Lock-in refers to those business model elements that create switching costs or enhanced incentives for business model participants to stay and transact within the activity system. Imagine, for example, what it would practically mean to switch from the Apple hemisphere to the Android world. Services like iTunes, iCloud and so on not only generate additional income but also encourage loyalty when buying new electronic hardware.

Complementarities refer to the value-enhancing effect of the interdependencies among business model elements. Consider, for example, eBay, which offers a platform to conduct sales over the internet among individual buyers and sellers of used and new products. A key requirement for the platform to function properly is a payment mechanism that allows buyers to make credit card payments even when the seller does not have access to credit card services. PayPal, the 
$\{$ Box 1$\}$

\section{POKÉMON GO \\ A NEW BUSINESS MODEL FOR NINTENDO}

Most people associate Nintendo with the gaming consoles Wii or the handheld DS and with their popular games like Super Mario, Pokémon and others. Only a few years ago DS, 3DS XL, etc. could be found under almost every Christmas tree, but with the increasing omnipresence of smartphones and new and popular gaming apps, less and less was being said about these products. Also the WiiU was associated with modest graphics instead of great improvement.

However, in July 2016, Nintendo opened a new chapter: Pokémon GO was rolled out worldwide within a few days and exceeded all expectation. The monster hunt was suddenly possible in the "real" world with current smartphones, and millions started to move around and chase and fight Pokémon in public places. The Pokémon franchise has always been about wandering a virtual world collecting while training and fighting Pokémon against other players. Replacing the virtual with the physical world was easy enough to think of, but incredibly difficult to execute. The whole business model of Nintendo had to be reinvented.

The only thing that remained the same were the Pokémon characters. They now no longer inhabit Nintendo's own consoles but appear in a mixed reality created by mobile devices, Google Maps and the physical world. The new platform involved new structures, new governance and new revenue generation systems. A new co-developer, a new distribution system for the app and new forms of monetization had to be installed. At the moment, Pokémon GO's monetization model is fairly pedestrian -- gamers can buy in-game virtual goods to enhance gameplay. However, more interesting avenues will open up if it is successful in expanding beyond Pokémon fans. Since the game's mechanics require players to travel to specific locations, sponsored locations might become a massive revenue opportunity. Local businesses could pay to become a sponsored PokeGym or just become havens for rare Pokémon. Based on the foot traffic we have already seen at "hot" Pokémon GO locations, this could soon become a reality.

With their novel way of re-enacting Pokémon fights, Nintendo has succeeded in gaining a significant foothold in today's mobile world. While it is still too early to estimate the overall success of this mobile venture, it certainly seems that the new business model not only saved Pikachu, Pummeluff, Shiggy, etc. from oblivion but the whole company from a slow steady decline.

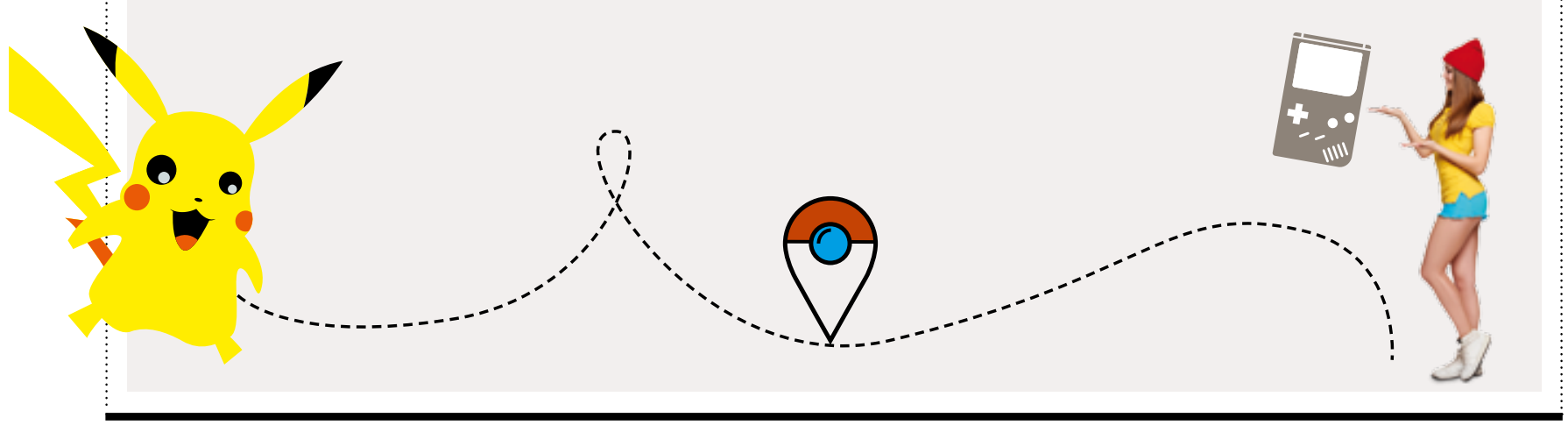




\section{$\gg$ \\ Content, structure and governance can be highly interdependent, and they need to be in line with the value creation and the revenue model of the company.}

online payment company that eBay acquired, offers such a function, facilitating trades that could not otherwise be completed. In other words, PayPal has a value-enhancing effect on the eBay activity system.

Efficiency refers to cost savings through the interconnections of the activity system. Consider Wal-Mart, which not only championed the concept of discount retailing but also designed an activity system that supports its low-cost strategy. An important activity within this system is logistics. Over time, Wal-Mart developed highly sophisticated processes, such as cross-docking, unrivaled in the industry. These processes help the company to keep its costs lower than its competitors, giving Wal-Mart an important competitive advantage.

Each of these value drivers enhances the total value-creation potential of a business model but when combined, they can be even more powerful.

Seeing the whole picture /// Content, structure and governance can be highly interdependent, and they need to be in line with the value creation and capture goals of the company, such as its revenue model, which could be referred to as the raison d'être, or the WHY of the business model. Making changes to a company's whole activity system rather than optimizing individual activities such as production requires systemic and holistic thinking, which can be demanding. When responding to a crisis, operating in tough economic times or taking advantage of a new opportunity, rethinking an entire business model may not always be the first thing on a manager's mind. This is particularly true when the level of resistance to change is predicted to be high. As a result, choices about business model design often go unchallenged for a long time - sometimes for too long a time. In disruptive and quickly changing environments, seeing the whole picture and acting upon it early can be a matter of corporate survival.

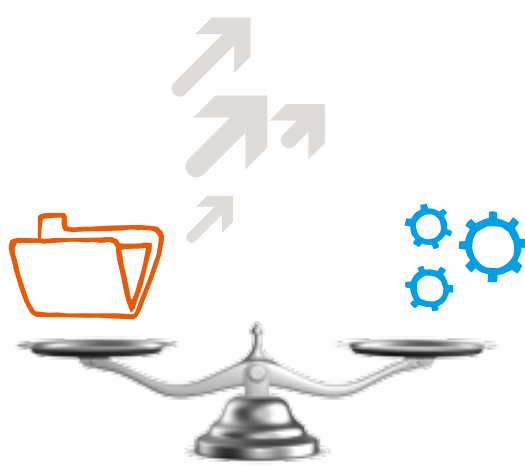

\section{FURTHER READING}

Amit, Raphael; Zott, Christoph (2015):

"Business Models" "In International Encyclopedia of the Social \& Behavioral Sciences, 2nd Edition,"

Vol. 3, edited by J. D. Wright, pp. 33-36.

Amit, Raphael; Zott, Christoph (2012):

"Creating Value Through Business Model Innovation,"

Sloan Management Review, Vol. 53 (3), pp. 41 - 49.

Zott, Christoph; Amit, Raphael (2015):

"Business Model Innovation: Towards a Process Perspective," in C. Shalley, M. Hitt, J. Zhou (Eds.),

Oxford Handbook of Creativity, Innovation, and Entrepreneurship: Multilevel Linkages.

Oxford University Press, New York: NY, pp. 395-406.

\section{Zott, Christoph (2016):}

"How to Innovate in Business Models: Changing The Way The Company Does Business," IESE Alumni Magazine, No. 140 ( January-March), pp 24-27.

http://www.tech-thoughts.net/2016/07/pokemon-goand-business-model-innovation.html\#.WDLRsLlMAXg (Nov. 21, 2016) 